\title{
Using Longwave Infrared Hyperspectral Imaging for a Quantitative Atmospheric Tracer Monitoring in Outdoor Environments
}

\author{
Eitan Hirsch, Eyal Agassi, Alon Manor
}

Environmental Physics Department, Environmental Sciences Division, Israel Institute for Biological Research, Ness Ziona, Israel Email: eyala@iibr.gov.il

How to cite this paper: Hirsch, E., Agassi, E. and Manor, A. (2021) Using Longwave Infrared Hyperspectral Imaging for a Quantitative Atmospheric Tracer Monitoring in Outdoor Environments. International Journal of Geosciences, 12, 233-252. https://doi.org/10.4236/ijg.2021.123014

Received: January 29, 2021

Accepted: March 19, 2021

Published: March 22, 2021

Copyright () 2021 by author(s) and Scientific Research Publishing Inc. This work is licensed under the Creative Commons Attribution International License (CC BY 4.0).

http://creativecommons.org/licenses/by/4.0/ (c) (i) Open Access

\begin{abstract}
Quantitative real-time retrieval of concentration-lengths (CL) through gaseous plumes is an important tool for environmental monitoring, enabling remote monitoring of emissions from industrial facilities and risk assessment in scenarios of toxic gas releases. The adoption of LWIR (Long Wave InfraRed) hyperspectral imaging as a leading technique for remote gas plume detection paved the way for an introduction of a precise CL estimation and two-dimensional (2D) mapping. A novel methodology for evaluating and characterizing the performance of a retrieval algorithm is presented. The algorithm utilizes state-of-the-art retrieved hyperspectral $2 \mathrm{D}$ mapping and is applied on a series of localized atmospheric tracer gas $\left(\mathrm{SF}_{6}\right)$ releases in monitored environmental conditions. The retrieved CL distributions are compared to a numeric atmospheric T\&D (Transport and Diffusion) model. Satisfactory agreement between retrieved and simulated CL prediction is manifested, and the uncertainty involved is quantified. Possible sources for the remained discrepancies between retrieved and simulated CL values are characterized, and methods to minimize them are discussed.
\end{abstract}

\section{Keywords}

Hyperspectral, Infrared, Gaseous Plumes, Concentration-Length, Quantification, Atmospheric Transport and Diffusion (T\&D) Model

\section{Introduction}

Standoff sensing of hazardous gaseous plumes is a well-known technique. Some of the most common applications are detection and identification of CWAs and TICs (Chemical War Agents and Toxic Industrial Compounds), detection of 
leaks and other sources of fugitive emissions and monitoring of smokestack emissions [1] [2] [3] [4] [5]. The ability of remote sensing techniques to yield estimations of concentration, averaged over an extended optical path (CL, Concentration Length) is widely utilized for single path instruments. For example, long-term source-rate estimation can be performed by measuring CL over a certain segment downwind of a localized gas source and matching the time-averaged results with a dispersion model (e.g., [6]).

Retrieval algorithms which include 2D quantitative real-time imaging (e.g., [7] [8] [9] [10]), have an even greater potential. The ability of attaining a 2D image in which every pixel corresponds to a real-time CL value, enables plume tracking, real-time risk assessment and decision support in events of TIC/CWA dissemination. Additionally, this technique can augment conventional point concentration measurements in campaigns designed for the study of atmospheric transport and diffusion (T\&D).

Different environmental conditions, associated with environmental thermal contrasts, atmospheric disturbances, and optical properties of the sensed gas, can considerably affect the performance of retrieval algorithms, especially when the latter are applied at ranges of a few kilometers or more. Evidently, relevant conditions can hardly be replicated in laboratory conditions, limited in the attainable ranges, thermal contrasts, and atmospheric medium variability. Therefore, testing and validation in real outdoor environments is essential for quantifying the uncertainty involved in the CL assessment, and its dependence on various environmental conditions.

Still, lack of proper reference poses a considerable challenge for testing of retrieval algorithms in outdoor conditions. In the vast majority of cases, a parallel imaging technology to be used as a reference is unavailable. A possible solution is to test the algorithm by comparing the retrieval CL values to a corresponding value attained using a numeric T\&D model which simulates the $3 \mathrm{D}$ concentration field associated with a localized release of the sensed gas. In such a comparison, time-averaged CL values yielded by the retrieval method are compared to their counterpart simulated values obtained by numerically integrating over the modelled concentration field along appropriate lines of sight (LOS).

In order to reduce the model error inherent to any $T \& D$ model, the level of environmental complication associated with the turbulent gas dispersion should be minimized. For that sake, the release of gas should be well localized, continuous and in a controlled constant rate. The terrain should be flat, with uniform low coverage, and the wind behavior should be steady and persistent. Also, in order to properly infer input parameters for the dispersion model, careful local meteorological monitoring should take place. These restrictions may be the reason that, as far as the authors are aware, no attempt to apply this methodology for the testing of a quantitative imaging retrieval method for the outdoor environment has been reported.

This study manifests the above methodology using quantitative retrieval data 
obtained from a field experiment which includes several localized continuous releases of $\mathrm{SF}_{6}$ (Sulfur hexafluoride) tracer gas in various daytime conditions. Data acquisition relies on a state-of-the-art LWIR hyperspectral sensor, yielding superior performance compared to wide-band sensors, especially considering the specific tracer gas ([3] [7] [10]-[15]). Meteorological and source parameters are monitored and subsequently used as input to a Gaussian T\&D model simulating the time-averaged $3 \mathrm{D}$ concentration distribution within the plume. CL values are calculated by numerically integrating through the plume, creating a $2 \mathrm{D}$ simulated image that is subsequently compared to the quantitative retrieval imagery.

The ability of the methodology to characterize the performance of the retrieval algorithm is exemplified by addressing several issues including the spatial structure of the attained plume, qualitative point to point comparison, and overall mass reconstruction. Discrepancies are characterized, and insight is gained regarding the involved uncertainty.

The rest of the manuscript outline is as follows. The methods section includes a description of the experimental setup, the CL retrieval algorithm, the applied Gaussian T\&D model, and an outline of the comparison methodology, the Results section details the comparison, and the last section finalizes the study, discussing our findings and outlining future directions.

\section{Methods}

\subsection{Experimental Setup}

As mentioned earlier, a field test was carried out in order to collect a large and well-defined database. Obtaining a reliable data set which is acquired in a dedicated field test is a critical step towards a development of a trusted and applicable retrieval method. We will begin with a description of the main components of our experimental setup, focusing on the unique hyper-spectral sensor used for the current research. Being the key measurement instrument our sensing is based on, it requires a detailed description for a better understanding of the proposed retrieval and the validation methods.

\subsubsection{HyperCam Sensor}

The HyperCam (Telops, Canada) is a relatively lightweight and compact hyperspectral-imaging sensor which is based on Fourier Transform Infrared (FT-IR) technology [2]. The sensor couples a cooled LWIR MCT FPA (Long Wave InfraRed Mercury Cadmium Telluride Focal Plane Array) with a Michelson type of FT-IR interferometer. The sensor is integrated with its own built-in radiometric calibration sub-system and electronics which allows an accurate radiometric calibration and efficient NUC (Non-Uniformity Correction) and bad pixels detection and replacement (BPR). The main advantage of the sensor is its flexible spectral resolution due to the use of Michelson type interferometer (at the expense of adding an inevitable trade-off with data cube acquisition time). This 
flexibility enables us to choose the optimal working point in order to retrieve the $\mathrm{CL}$ of the gaseous tracer with the required accuracy (previous experimental works have shown that a spectral resolution of $4-6 \mathrm{~cm}^{-1}$ is an acceptable choice for $\mathrm{SF}_{6}$ [12]. The sensor can be operated either from the ground, or from an airborne platform ([16] [17] [18]). Due to its maturity and its easy operation method, the HyperCam sensor has gained popularity in the scientific and applied research communities and it is widely used today for many applications: standoff chemical detection and identification of gases (CWAs \& TICs); standoff chemical detection and identification of surface contaminants; unexploded ordnance and landmines detection; detection of mines and improvised explosive devices; military target infrared signature acquisition and analysis; leak detection; pollution monitoring, standoff emission characterization of smokestacks and more ([5] [18]-[24]). A list of the main characteristics of the HyperCam sensor is found in Table 1.

During the field test, the sensor was operated at a spectral resolution of 4 $\mathrm{cm}^{-1}$, which yields a data acquisition rate of 1 data-cube per 7.5 seconds. The obtained raw data was recorded on a hard disk drive and transferred through an Ethernet link for pre-processing which included a NUC procedure: gain, offset, bad pixels replacement and fast Fourier transform (FFT) to obtain the spectral information. The NUC parameters were calculated from a two-point calibration acquisition sequence of 16 data-cubes for each BB (Black Body) temperature. This pre-processing procedure yielded a time series of calibrated data-cubes that were ready for the operation of a CL retrieval method which will be described in the following. A X0.25 telescope was used to cover the maximal available field of view of the gas plume.

Table 1. Main features of HyperCam Sensor (see also Figure 1).

\begin{tabular}{ccc}
\hline Parameter & Values/Features & Unit \\
\hline Spectral Range & $7.7-11.8$ & $\mu \mathrm{m}$ \\
Spectral Resolution & Up to 0.25 & $\mathrm{~cm}^{-1}$ \\
FPA Format & $320 \times 256$ & pixels \\
Field of View (standard) & $6.4 \times 5.1$ & $\mathrm{deg}$ \\
Field of View (×0.25 telescope) ${ }^{*}$ & $25.6 \times 20.4$ & $\mathrm{deg}$ \\
Typical NESR (noise equivalent spectral radiance) & 20 & $\mathrm{nW} / \mathrm{cm}^{2} \mathrm{sr}^{-\mathrm{cm}^{-1}}$ \\
Radiometric Accuracy & $<1.0$ & ${ }^{\circ} \mathrm{K}$ \\
Acquisition Software & Reveal Pro & \\
Data Transfer & Reveal D \& I & \\
Power Consumption & Camera Link & $\mathrm{W}$ \\
Weight & 180 & $\mathrm{~kg}$ \\
Operating Temperature & 31 & ${ }^{\circ} \mathrm{C}$ \\
\hline
\end{tabular}

${ }^{\star} \mathrm{X} 4$ telescope is another available option. 


\subsubsection{Atmospheric Tracer}

A pure $\mathrm{SF}_{6}$ gas was used as a sensitive and detectable atmospheric tracer. $\mathrm{SF}_{6}$ is widely used as a tracer due to the combination of its safety, cost, the availability of highly sensitive point concentration sampling and analysis methods, and distinctive high absorption IR spectrum. Due to all of these properties, its use as an atmospheric tracer has a long history and it has been used extensively as a simulant for toxic gaseous. The gas was continuously released from original pressurized cylinders for a duration ranging from 15 to 30 minutes in a steady flow rate ranging from $2 / 3$ to $1 \mathrm{~kg} / \mathrm{min}$ for each different release. The same release point was used throughout the campaign.

\subsubsection{Meteorological Sensors}

Two meteorological masts were erected in the field. The first one was positioned at the release point, and included a sonic anemometer mounted at a height of 3 meters above ground (hereafter - the release point station). The second mast was located downwind at a distance of 500 meters from the release point and included two sonic anemometers mounted at the heights of 4 and 16 meters above ground (hereafter - the middle station). The obtained data was used to assess the atmospheric stability criteria during the release. Figure 1 shows part of the experimental setup on the field.

\subsubsection{Field Test Runs}

Three controlled trials were conducted on three separate days. The general wind direction was from the same sector in all the releases, but with varying atmospheric stability. The field test area was a wide flat desert terrain with sparse very low vegetation. Therefore, it forms an excellent area for "classical" dispersion models validation (see Figure 2).

The text will henceforth refer to the field trails (releases) as IOPs (Intensive Observation Periods) 1, 2 and 3, respectively. Table 2 summarizes some relevant details concerning each of the IOPs.

The campaign was held at the beginning of July in an extremely dry desert basin. Sunset was about 19:45 local time and the sky was perfectly clear. Figure 3 shows the mutual positions of the HyperCam sensor, the dissemination point and a point horizontally located at the center of the Field Of View (FOV). The HyperCam sensor was positioned on a small hill, leading to a vertical difference of 20 meters between the sensor and the plateau.

Table 2. Relevant technical and meteorological parameters of the $\mathrm{SF}_{6}$ releases. Atmospheric stability criteria are defined by [25].

\begin{tabular}{cccc}
\hline IOP & $\begin{array}{c}\text { Time of release start } \\
\text { (local time) }\end{array}$ & $\begin{array}{c}\text { Release duration } \\
{[\mathrm{min}]}\end{array}$ & $\begin{array}{c}\text { Release rate } \\
{[\mathrm{Kg} / \mathrm{min}]}\end{array}$ \\
\hline 1 & $19: 42$ & 15 & 1 \\
2 & $14: 30$ & 15 & $2 / 3$ \\
3 & $16: 46$ & 30 & $2 / 3$ \\
\hline
\end{tabular}




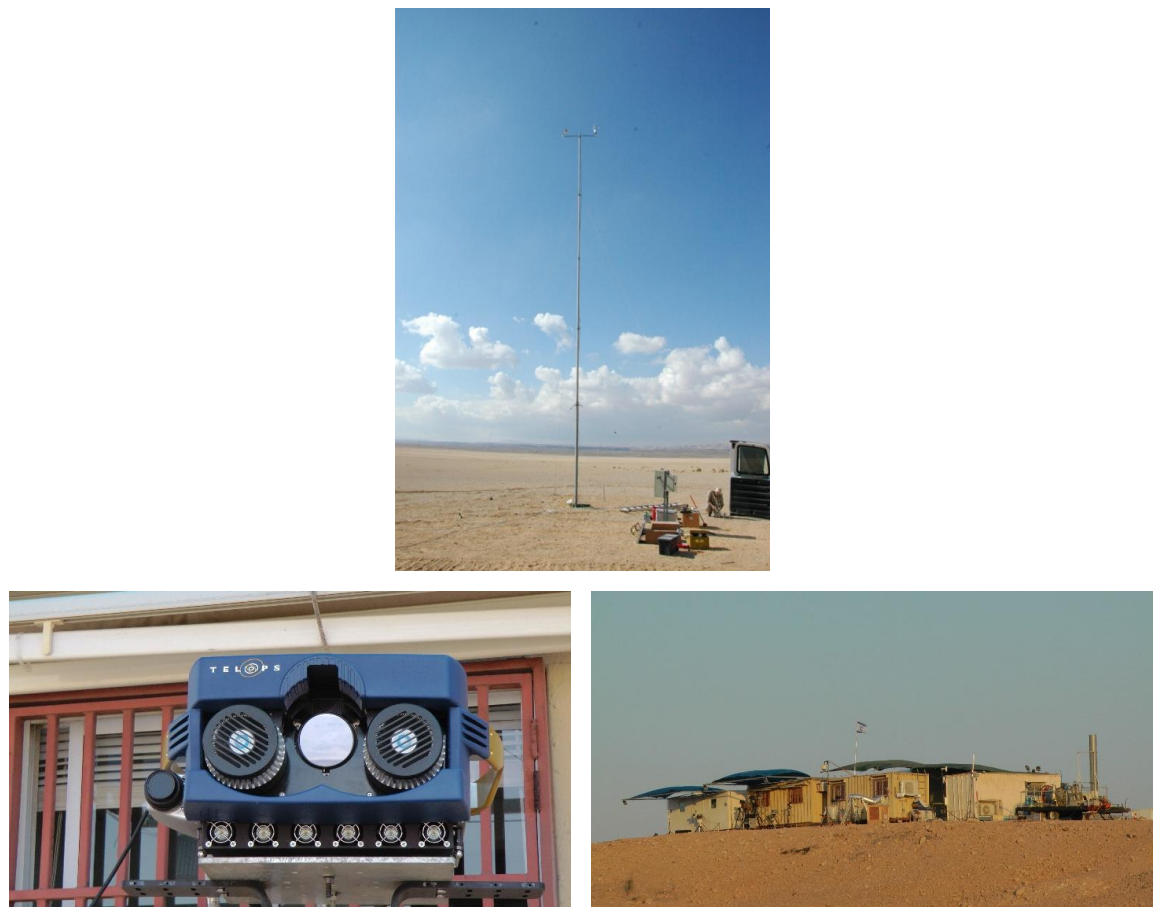

Figure 1. Experimental setup facilities. Top left—meteorological mast; Top right-command post; Bottom-HyperCam sensor.

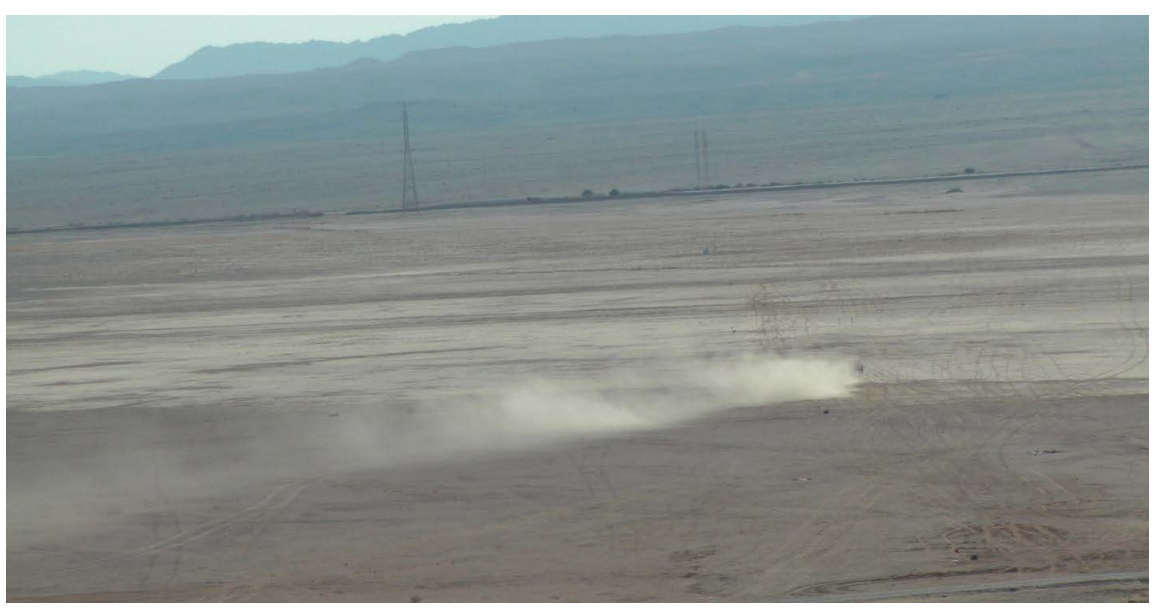

Figure 2. General view of the field test area and the surroundings of the release point (The dust arises from moving vehicle).

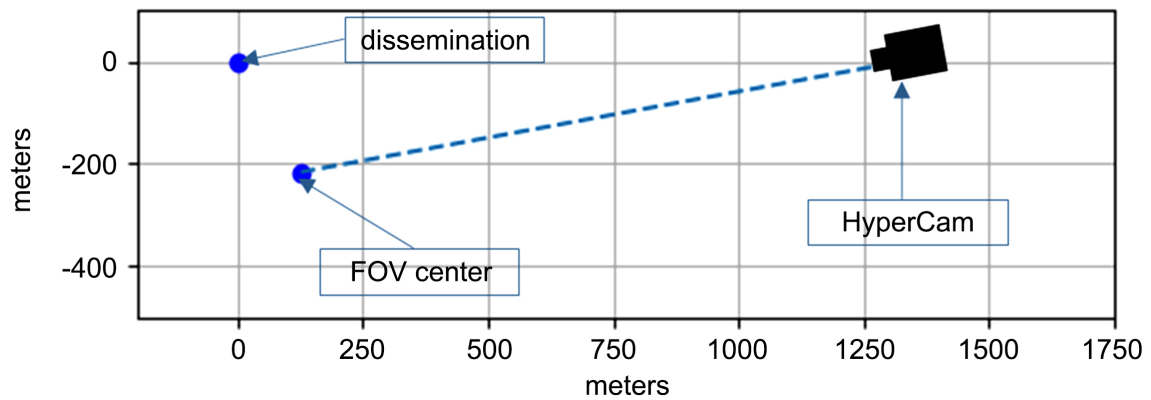

Figure 3. Relative positions of the dissemination point (located in the origin), the HyperCam sensor, and the point horizontally located at the center of the Field Of View (FOV). 


\section{Concentration-Length (CL) Retrieval Using Hyperspectral Imaging in the LWIR}

The first step and the most critical one towards CL retrieval is the estimation of the expected signal due to the presence of a $\mathrm{SF}_{6}$ gaseous plume inside the sensor's FOV. Figure 4 shows the mass absorption of neat $\mathrm{SF}_{6}$ molecules. The gas is characterized by a strong and narrow spectral feature that enables an easy detection and identification of its presence in the atmosphere.

The absorption spectrum of the gas was resampled in order to be compatible with the spectral resolution of HyperCam sensor, and the transmittance of the gas was calculated in the relevant spectral band (centered at a wavelength of $10.54 \mu \mathrm{m}$ and a spectral width of $4 \mathrm{~cm}^{-1}$ ) according to:

$$
\tau=\int_{\lambda_{1}}^{\lambda_{2}} \mathrm{e}^{-\alpha(\lambda) C L}
$$

where $\tau$ is the transmittance of $\mathrm{SF}_{6}$ plume of a given CL in the spectral band between $\lambda_{1}$ and $\lambda_{2} . \alpha(\lambda)$ is the mass absorption of $\mathrm{SF}_{6}$ as a function of wavelength. $C L$ is defined by an integral on the concentration along LOS:

$$
C L \equiv \int_{0}^{R} C(r) \mathrm{d} r
$$

where $C(r)$ is the concentration at a distance of $r$ from the sensor. $R$ is the LOS endpoint (can be $\infty$ ). We have omitted the explicit optical spectral resolution function, since it should have a minor effect on such a narrow absorption band. Figure 5 shows the expected transmittance of an $\mathrm{SF}_{6}$ gas plume at a center wavelength of $10.54 \mu \mathrm{m}$ according to Equation (1) in the HyperCam's sensor spectral resolution and sampling versus the $\mathrm{CL}$ (concentration-length) of $\mathrm{SF}_{6}$ over the plume.

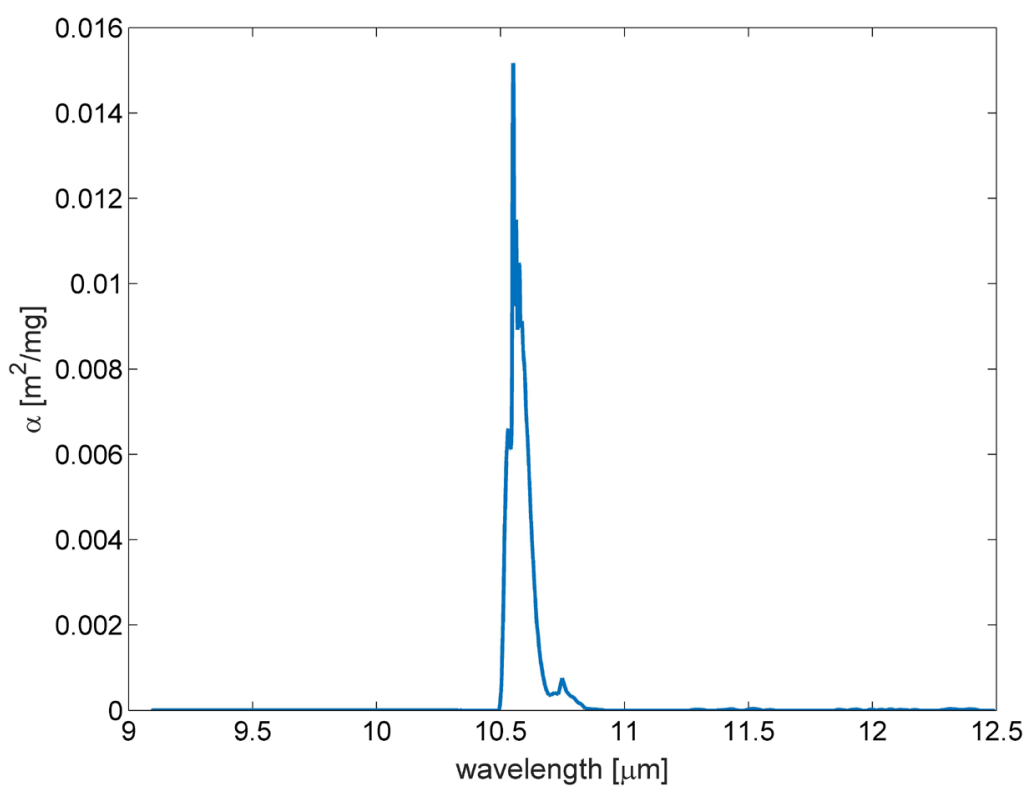

Figure 4. Mass absorption of an $\mathrm{SF}_{6}$ as a function of wavelength (Source: HITRAN open data base [26]). 


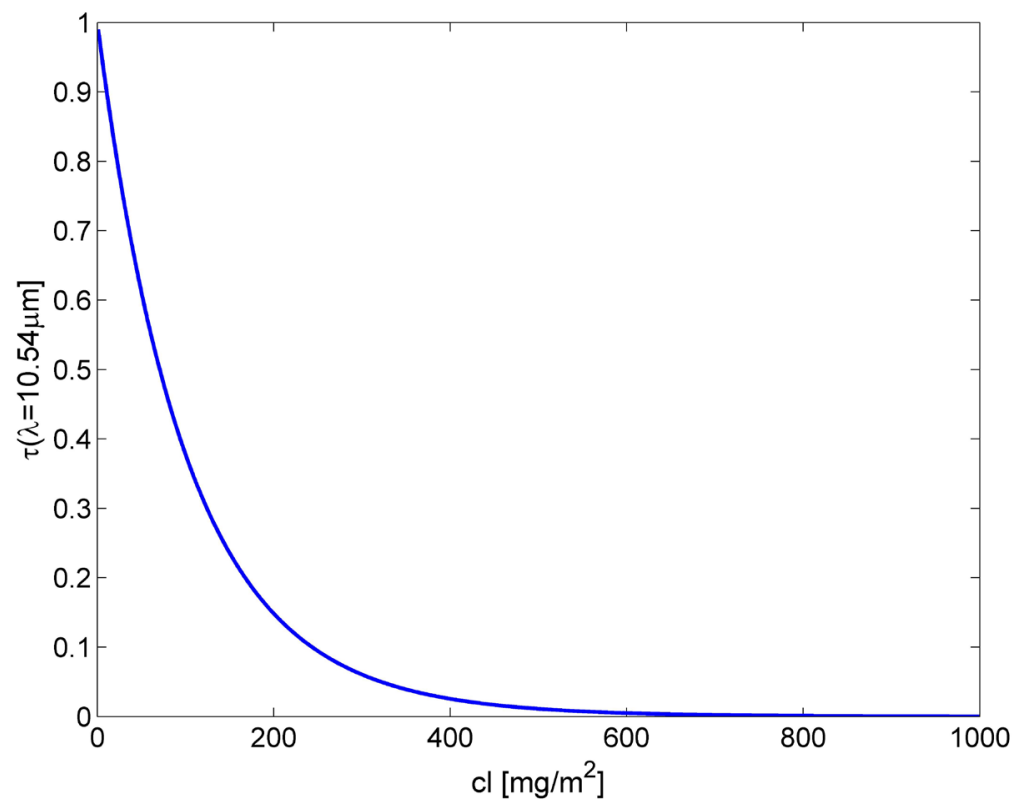

Figure 5. $\mathrm{SF}_{6}$ transmittance at a wavelength of $10.54 \mu \mathrm{m}$ vs. the concentration-length of the gas.

The effect of the presence of a gas plume on the clear background signal of the sensor in the LWIR band has been widely described and discussed in the past [12]. Assuming the thermal contrast in the scene is relatively small (few degrees), the signal obtained by the sensor can be approximated as:

$$
T_{\text {sensor }}(\lambda)=T_{b g}(\lambda) \tau(\lambda)+(1-\tau(\lambda)) T_{\text {air }}
$$

This leads to:

$$
\tau(\lambda)=\frac{T_{\text {sensor }}(\lambda)-T_{\text {air }}}{T_{b g}(\lambda)-T_{\text {air }}}
$$

Looking into the Equation (3), it is clear that we must accurately assess both the air temperature and the background image effective temperature without the interference of the gas in order to extract the transmittance of the gas plume at a certain IFOV (instantaneous field of view) inside the total FOV.

In light of the above, our retrieval algorithm includes the following steps:

1) An acquisition of at least one hyperspectral data-cube of the scene prior to the dissemination of the gas $\left(T_{b g}\right)$.

2) An estimation of the two-dimensional air temperature matrix $\left(T_{\text {air }}\right)$ by using a wavelength which is characterized by a very low atmospheric transmittance due to water vapor absorption.

3) A continuous acquisition of data-cubes during the gas release $\left(T_{\text {sensor }}\right)$.

4) Using Equation (30 in order to extract the two-dimensional transmittance matrix $(\tau)$.

5) By using the relation between $\tau$ and CL (Figure 2), finding the equivalent $\mathrm{CL}$ corresponding to the specific $\tau$ for every pixel, yielding a two-dimensional CL matrix. 
6) A repetition of stages $c$. and d. during the release of the gas.

Figure 6 and Figure 7 demonstrate the process chain of the algorithm.

As mentioned in previous sections, the obtained 2D CL maps served as an experimental database for the validation phase using an atmospheric transport and diffusion model, as will be introduced in the next subsections.
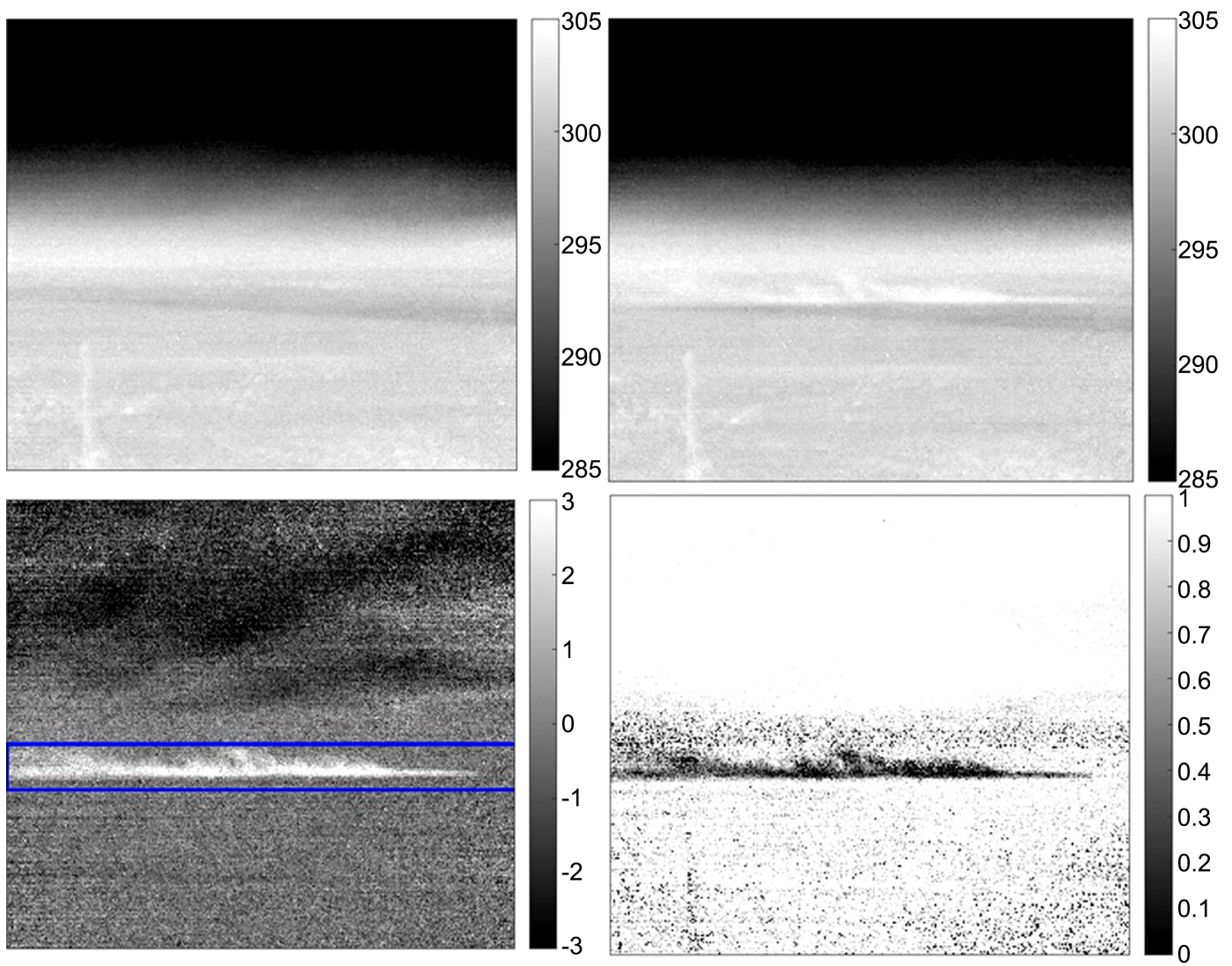

Figure 6. The retrieval process chain. Top left: background image at a wavelength $10.54 \mu \mathrm{m}$. Top right: $\mathrm{SF}_{6}$ plume (warm over the background at wavelength of $10.54 \mu \mathrm{m}$ ) during the release [K]. Bottom left: subtraction image of upper images $[\mathrm{K}]$. The blue rectangle denotes the AOI (area of interest) which was later used to calculate the $\mathrm{CL}$ values. Bottom right: $\mathrm{SF}_{6}$ transmittance image as derived by the algorithm.
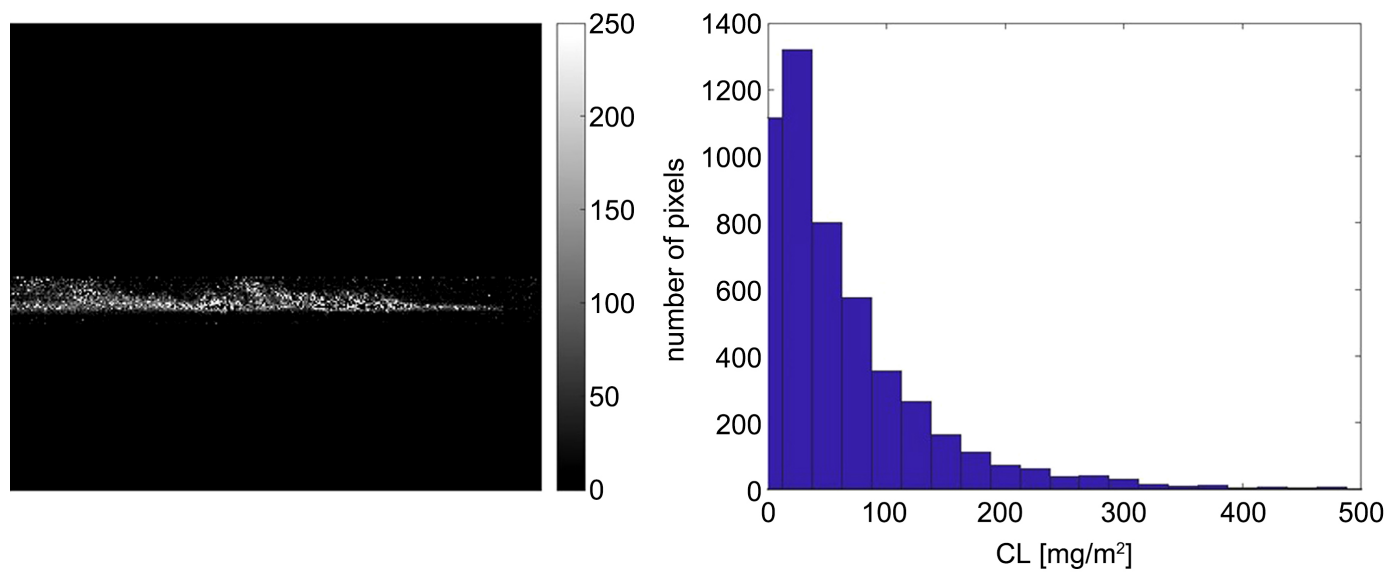

Figure 7. Left: concentration-length (CL) image $\left[\mathrm{mg} / \mathrm{m}^{2}\right]$. Right: CL histogram of the left side hand image. 


\section{Atmospheric Transport and Diffusion (T\&D) Model}

In order to obtain modeled three-dimensional concentration fields, the simple Gaussian plume model ([25]) was used

$$
C(x, y, z)=Q\left(\pi u \sigma_{z}(x) \sigma_{y}(x)\right)^{-1} \mathrm{e}^{-\frac{1}{2}\left[y^{2} / \sigma_{y}^{2}(x)+z^{2} / \sigma_{z}^{2}(x)\right]}
$$

This equation describes the three-dimensional steady-state concentration field induced by a ground-level point source releasing a passive tracer to the atmosphere at a rate $Q \mathrm{~kg} / \mathrm{sec}$. $u$ is the wind speed (meters/sec) as measured 10 meters above ground. The coordinate system is Cartesian, where the $z$ coordinate points in the vertical direction and the $x$ coordinate is aligned parallel to the mean wind direction. The origin is set at the source location. $\sigma_{y}(x)$ and $\sigma_{z}(x)$ are empirical functions describing the width of the plume in the crosswind horizontal $(y)$ and the vertical $(z)$ dimensions. This plume width grows monotonically with the downwind distance from the source, according to the effect of turbulent diffusion by stochastic wind fluctuations in the horizontal and vertical dimensions. The choice of $\sigma_{y}(x)$ and $\sigma_{z}(x)$ depends on the state of the atmospheric boundary layer's static stability, which can be described by classes from A to F, where A corresponds to a convective atmosphere, and F to a stably stratified boundary layer. In this paper, the plume width functions recommended by [27] for open country conditions were used (Table 3 ). The actual physical nature of the experimental test area clearly justifies this choice.

An illustration of the 3D concentration field described by Equation (5) is given in Figure 8, through iso-concentration contours (further reference to this figure will follow).

Following [28] (see Table 4), the stability class for daytime conditions was inferred by the wind speed and insolation conditions. As recommended in [29] $350 \mathrm{~W} / \mathrm{m}^{2}$ and moderate as falling in-between.

An alternative classification scheme used in some of the comparisons is the sigma theta scheme ([30], Table 5), in which the stability is determined by $\sigma_{\theta}$, the standard deviation of the wind direction.

Table 3. $\sigma_{y}(x)$ and $\sigma_{z}(x)$ for different atmospheric stability conditions.

\begin{tabular}{ccc}
\hline Stability class & $\sigma_{y}(x)$, meters & $\sigma_{z}(x)$, meters \\
\hline A & $0.22 x(1+0.0001 x)^{-1 / 2}$ & $0.2 x$ \\
B & $0.16 x(1+0.0001 x)^{-1 / 2}$ & $0.12 x$ \\
C & $0.11 x(1+0.0001 x)^{-1 / 2}$ & $0.08 x(1+0.0002 x)^{-1 / 2}$ \\
D & $0.08 x(1+0.0001 x)^{-1 / 2}$ & $0.06 x(1+0.0015 x)^{-1 / 2}$ \\
E & $0.06 x(1+0.0001 x)^{-1 / 2}$ & $0.03 x(1+0.0003 x)^{-1}$ \\
F & $0.04 x(1+0.0001 x)^{-1 / 2}$ & $0.016 x(1+0.0003 x)^{-1}$ \\
\hline
\end{tabular}




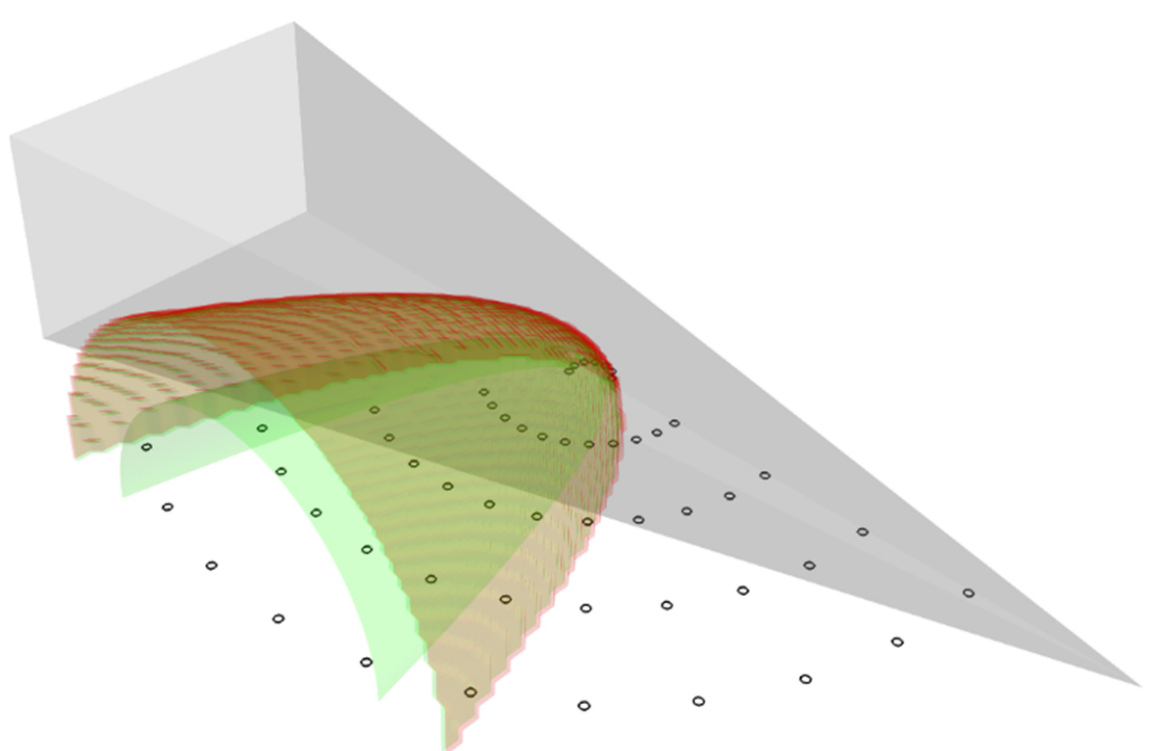

Figure 8. An illustration of the 3D concentration field described by Equation (5).

Table 4. The stability class for daytime conditions for different wind speed and insolation conditions.

\begin{tabular}{cccc}
\hline \multirow{2}{*}{ Surface wind speed, $\mathrm{m} / \mathrm{s}$} & \multicolumn{3}{c}{ Daytime insolation } \\
\cline { 2 - 4 } & Strong & Moderate & Slight \\
\hline 2 & A & A-B & B \\
$2-3$ & A-B & B & C \\
$3-5$ & B & B-C & C \\
$5-6$ & C & C-D & D \\
$>6$ & C & D & D \\
\hline
\end{tabular}

Table 5. The stability class for daytime conditions according to the sigma-theta scheme.

\begin{tabular}{cc}
\hline$\sigma_{\theta}$ & Daytime stability class \\
\hline$\sigma_{\theta}>22.5$ & $\mathrm{~A}$ \\
$22.5>\sigma_{\theta}>17.5$ & $\mathrm{~B}$ \\
$17.5>\sigma_{\theta}>12.5$ & $\mathrm{C}$ \\
$12.5>\sigma_{\theta}>7.5$ & $\mathrm{D}$ \\
\hline
\end{tabular}

\section{Comparison Methodology}

Due to the turbulent nature of atmospheric dispersion, the instantaneous concentration field is disordered and changes rapidly (Figure 9). The T\&D model estimates only the temporally averaged concentration values. Therefore, the retrieval data is averaged over a time period of 15 minutes to attain fields that are smooth enough for comparison with the Gaussian T\&D model.

Following this requirement, we define four time periods, where for each period, the meteorological conditions are given in Table 6. 
Table 6. Time ranges and meteorological conditions used for the comparison.

\begin{tabular}{|c|c|c|c|c|c|c|c|c|c|}
\hline \multirow{2}{*}{ ID } & \multirow{2}{*}{ Date } & \multirow{2}{*}{$\begin{array}{l}\text { Initial } \\
\text { time }\end{array}$} & \multirow{2}{*}{$\begin{array}{c}\text { Ending } \\
\text { time }\end{array}$} & \multirow{2}{*}{$\begin{array}{l}\text { Sky and insolation } \\
\text { irradiance } \\
\left(\mathrm{W} / \mathrm{m}^{\wedge} 2\right)\end{array}$} & \multirow{2}{*}{$\begin{array}{l}\text { Mean wind } \\
\text { speed }(\mathrm{m} / \mathrm{s})\end{array}$} & \multirow{2}{*}{$\begin{array}{l}\text { Mean wind } \\
\text { direction } \\
\text { (deg, met.) }\end{array}$} & \multirow{2}{*}{$\sigma_{\theta}$} & \multicolumn{2}{|c|}{ Atmospheric stability class } \\
\hline & & & & & & & & Pasquill & $\sigma_{\theta}$ \\
\hline 1 & $9 / 7$ & 19:42 & 19:57 & $<10$ & 7.6 & 335 & 8 & $\mathrm{D}$ & $\mathrm{D}$ \\
\hline 2 & $14 / 7$ & $14: 30$ & 14:45 & 890 & 4.6 & 333 & 29 & B & $\mathrm{A}$ \\
\hline $3 a$ & $16 / 7$ & $16: 46$ & $17: 01$ & & 3 & 1 & 25 & B & $\mathrm{A}$ \\
\hline $3 b$ & $16 / 7$ & $17: 01$ & $17: 16$ & 410 & 4.9 & 358 & 19 & C & B \\
\hline
\end{tabular}
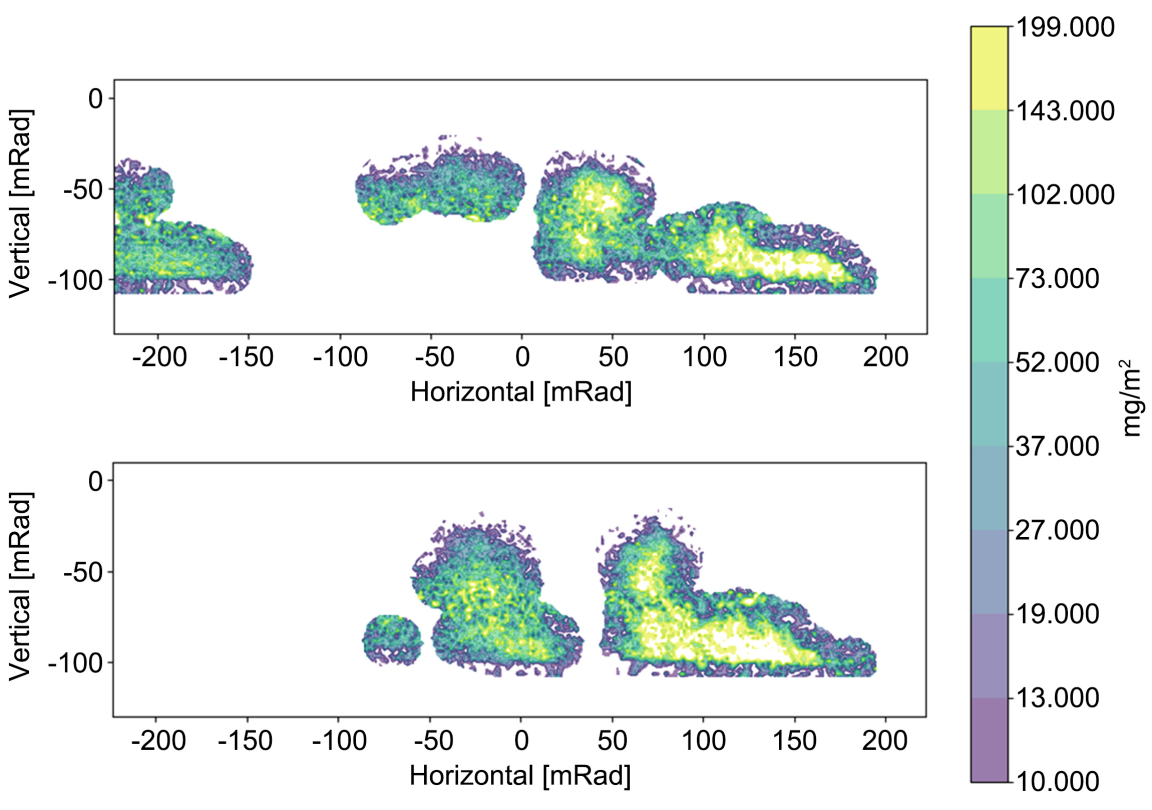

Figure 9. Two instantaneous CL distributions, acquired on the $16^{\text {th }}$ of July. The upper one refers to the time 17:05 and the lower one refers to 17:06.

Simulated CL images are calculated by numerically integrating over LOSs, originating at the sensor's location, crossing the 3D calculated concentration field (see Figure 8).

To enable pixel to pixel comparison, LOSs used for numerical integration through the $3 \mathrm{D}$ plume are designed to replicate the same spatial resolution and field of view of the retrieved data.

As discrepancies between retrieved and modelled CL values can be attributed to uncertainties both of the retrieval algorithm and of the T\&D model, we need to have some measure of the model uncertainty throughout our comparisons. For that sake, we evaluate the stability class in two different methods-the Pasquill method (Table 4) and the sigma theta method (Table 5), and where the attained stability classes are different, both cases are presented. Indeed, Table 6 shows that the stability classes yielded by the two methods differ by one class for most of the studied periods. Other parameters like the wind speed and direction are directly measured and therefore have less potential of incorporating uncertainty. 


\section{Results}

\subsection{Qualitative Comparisons}

For a qualitative impression of the attained plume shapes, iso-CL contours are presented (Figures 10-13), where the results of the retrieval algorithm are presented by filled contours, while unfilled contours, correspondingly color-coded, represent the simulated CL values. It is worth noting that for the ranges under consideration (about 1400 meters from the sensor to the release point as sketched in Figure 3), every $1 \mathrm{mrad}$ corresponds to about 1.5 meters. For the sake of brevity, these plots will be shown only for the Pasquill stability classification option.

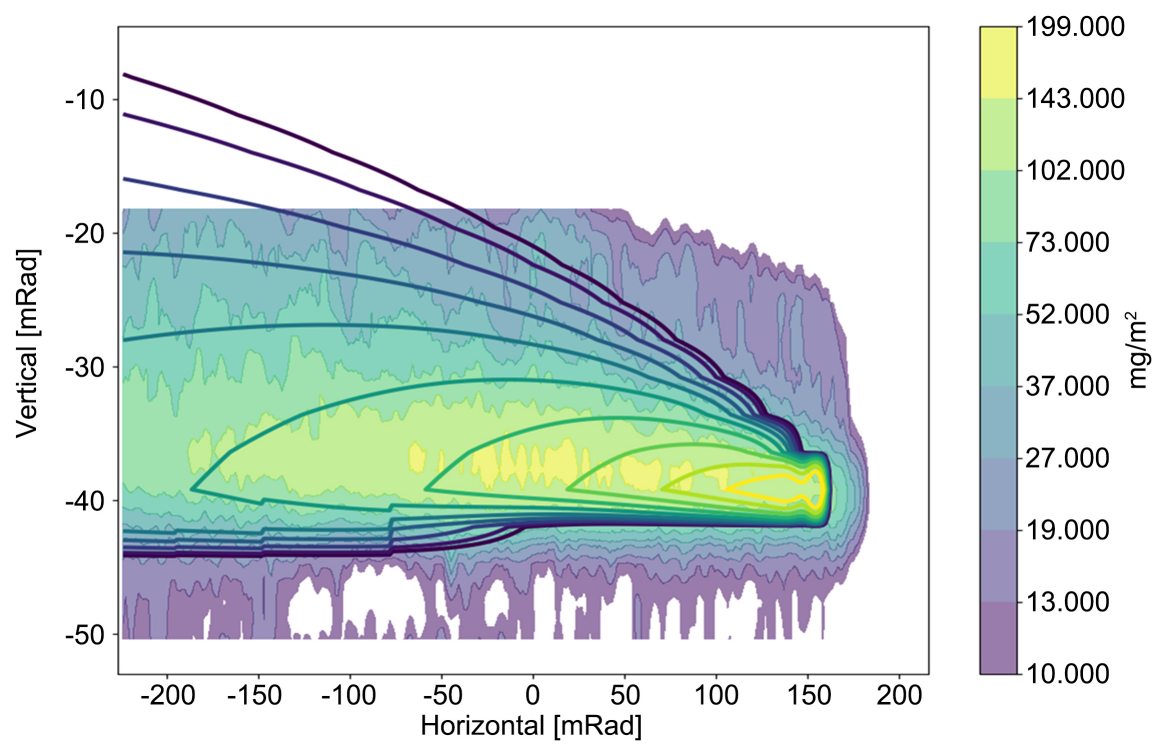

Figure 10. CL iso-contours, in $\mathrm{mg} / \mathrm{m}^{2}$, of period 1 (see Table 6). Retrieved data is depicted by filled semi-transparent contours, and thick unfilled contour lines mark the corresponding simulated plume.

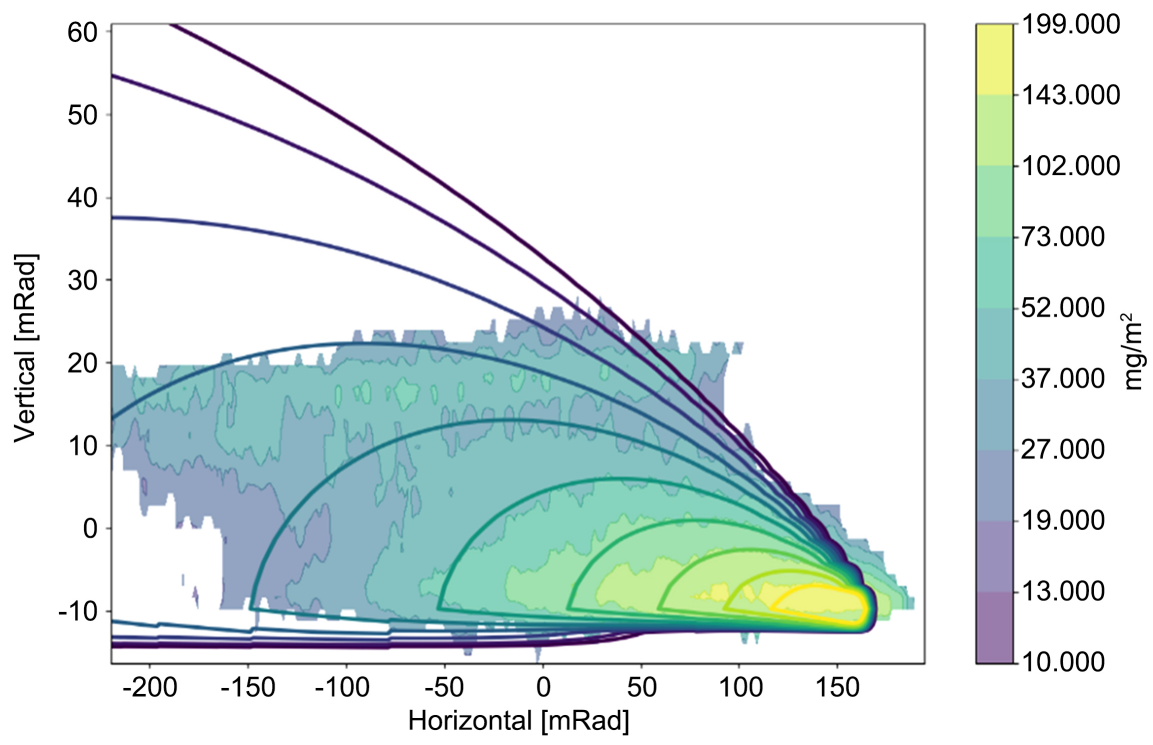

Figure 11. Like Figure 10, for period 2. 


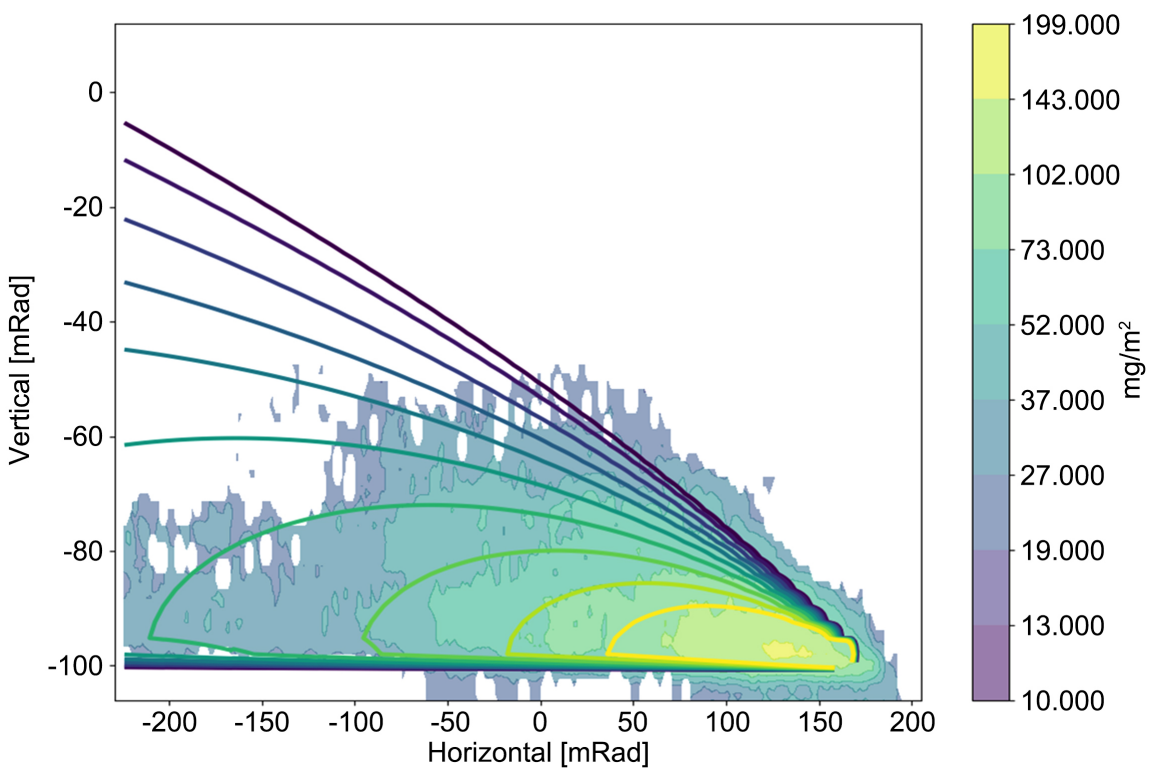

Figure 12. Like Figure 10, for period 3a.

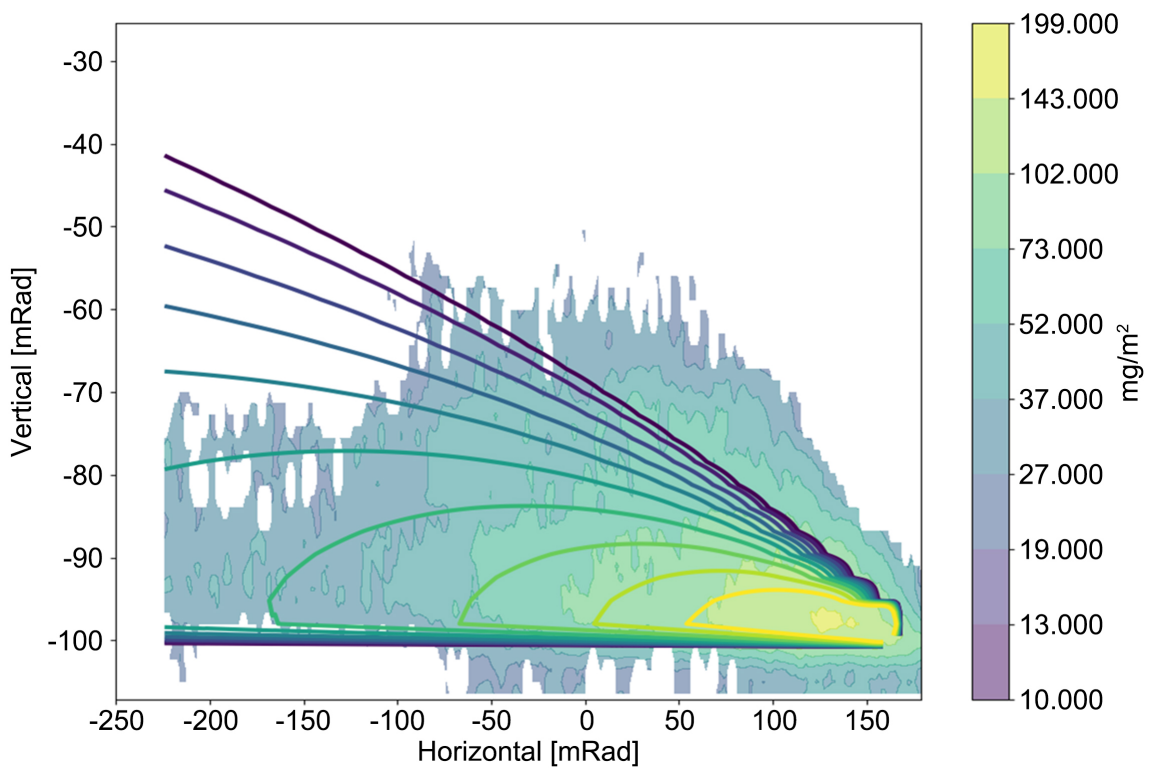

Figure 13. Like Figure 10, for period 3b.

The general shapes of the contours are replicated down to values of about 30 $50 \mathrm{mg} / \mathrm{m}^{-2}$, which seems to mark the threshold sensitivity of the retrieval algorithm in the specific thermal contrast at the test run. The height of the contours and the downwind extent corresponds to the atmospheric stability class. For neutral stability (Figure 10) the plumes are vertically shallower and retain high concentration downwind, while for an unstable atmosphere (periods 2-3b) the plumes extend vertically on the expense of lower concentration values downwind.

As a result of the height difference between the HyperCam sensor and the plume (see section 2.1.4), some LOSs which correspond to the bottom part of the 
FOV do not cross through the full horizontal extent of the plume but are terminated by the ground a short distance away. This is especially noted for periods in which the mean wind direction creates a larger angle with the orientation of the sensor. As a result, both Figure 9 and Figure 10 shows areas of lower concentration length at the bottom part of the FOV, both for the retrieved and for the simulated data. Additionally, some artifacts that have to do with the retrieval algorithm can be recognized. Like low CL values 10 - 20 meters above the release point in Figure 9 and a miss-interpretation associated with the border between the remote mountains and the sky (Figure 10).

\subsection{Mass Conservation along the Plume}

Conservation of mass can be utilized to compare retrieved to simulated concentration length data in a manner that is robust to the choice of a specific T\&D model and parameters. Considering a time-average concentration field, and steady source and meteorology conditions, the total concentration integrated over a plane perpendicular to the wind direction (Plane Integrated Concentration, PIC), should not depend on the windward position of the plane. This principle is reflected by the basic Gaussian formula, Equation (5), which, after integrating over $y$ and $z$, retains a constant value of $Q / u$, regardless of the specific functional form of $\sigma_{y}(x)$ and $\sigma_{z}(x)$.

In the following analysis (Figure 14), integration over every column of pixels in the retrieved $/$ simulated images is performed, and the resulting value is regarded as PIC over a plane formed by the LOSs in the column. For period 1 (Figure 14(a)), the data shows the expected behavior, approaching a constant, however, the value is more than two time higher than the corresponding simulated value. For the other periods, taking part in unstable conditions, a similar pattern is evident. After a distance of about 10 meters downwind from the source, in which the retrieved PIC value is underestimated, a constant value is approached, which is about 1.3 to 2 times higher than its modelled counterpart. After sustaining a somewhat constant PIC, for another 100 - 200 meters downwind, the PIC falls as retrieved CL data falls below the sensitivity threshold of the retrieval algorithm. Some possible factors for this discrepancy will be discussed in the last section. However, we consider the results as a good match for quantitative analysis, when all the uncertainties are considered.

\subsection{Direct Comparison}

We finalize this section with a direct pixel-to-pixel comparison between the simulated and the retrieved data using conventional scatter plots (Figure 15). The uncertainty associated with the T\&D model prediction is reflected by running the model with stability class yielded by the Pasquill method (blue circles) and by the sigma-theta method (orange circles). A solid red curve corresponds to the ideal trend, and two dashed red curves mark the values within a factor of two away from it. 

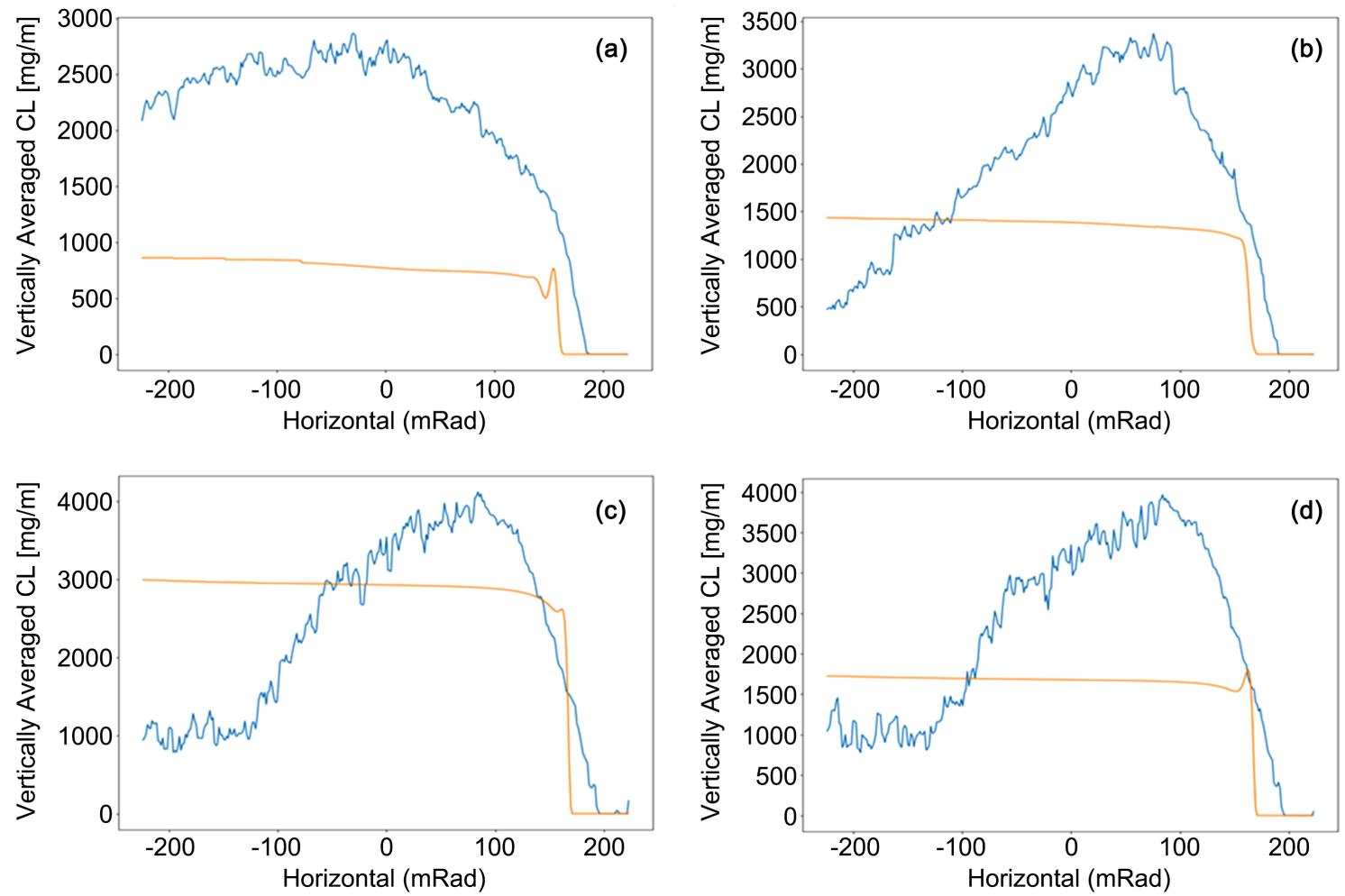

Figure 14. Plane integrated concentration $(\mathrm{mg} / \mathrm{m})$ for the retrieved data (blue curves) and for the corresponding simulated plumes (orange curves), for periods 1, 2, 3a and $3 \mathrm{~b}$ ((a), (b), (c) and (d), respectively).
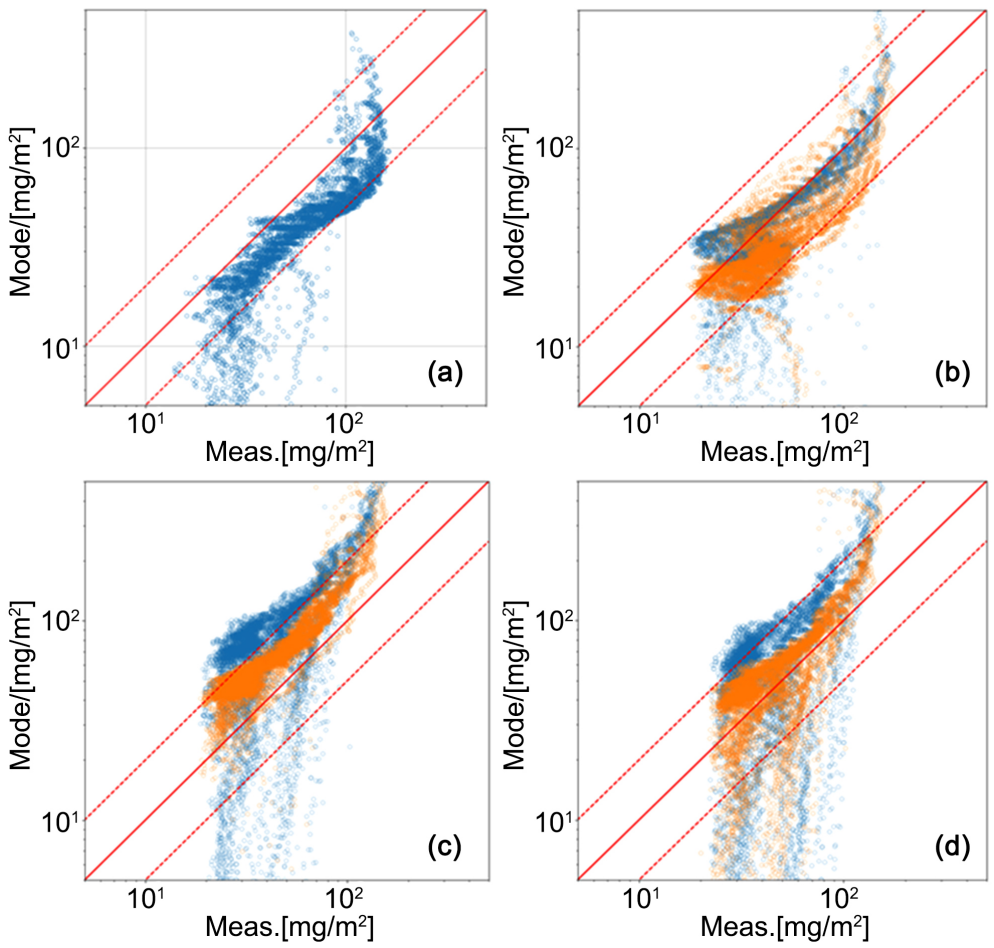

Figure 15. Scatter plots showing pixel-to-pixel comparison of the retrieved (horizontal axis) and the simulated (vertical axis) concentration length values, for periods $1,2,3 \mathrm{a}$ and $3 \mathrm{~b}(\mathrm{a}),(\mathrm{b}),(\mathrm{c})$ and (d), respectively). For cases where the stability class yielded by the Pasquill and the sigma-theta methods differ, both options are presented, where the first is represented by blue circles, and the latter by orange circles. 
Overall, for CL values ranging from 20 to $200 \mathrm{mg} / \mathrm{m}^{2}$, the retrieved and the modelled data agree within a factor of two or less. Another general feature that is the evident is reflected by a "banana" shape of the cloud of points. This reflects that the bias of the retrieved data compared to the simulated data depends on the concentration length. Additionally, for all the analyzed periods, some points are observed for which the retrieved value if around $20 \mathrm{mg} / \mathrm{m}^{2}$, but the modelled one is much lower (see the last paragraph in the previous section).

\section{Summary and Conclusion}

A novel methodology for studying the performance of remote quantitative $2 \mathrm{D}$ CL mapping of gaseous plumes by LWIR hyperspectral sensing has been introduced. The CL retrieval method is based on radiative transfer analysis and employs both high spectral and spatial resolutions of the acquired images for CL extraction and mapping. The suggested methodology relays on the conduction of a well-controlled and monitored field test of several gas releases at different atmospheric conditions. The obtained retrieved data is compared with a widely accepted T\&D model.

Overall, the 2D CL maps obtained by the model and the retrieval method agree satisfactorily well both in terms of plume shape and in terms of CL values. The applied methodology allows an analysis and characterization of the discrepancies, quantification of the involved uncertainty, and potentially a subsequent improvement in the retrieval algorithm.

The sources of the gap between the obtained CL by the model and the retrieval data are probably not due to process flaws and can be dived into two main categories: physical and instrumental. The physical detection limit arises mainly as a result of low SNR ratio (the detection threshold is a direct function of effective temperature difference between the air and LOS background and sensor sensitivity). The instrumental factors are:

1) Using boxcar for the integral in Equation (1) instead of the true spectral response of the FTIR in each band.

2) Ignoring axis dispersion that causes a radial spectral shift in the center wavelength.

It is the author's view that the current obtained quantitative match is fair for applications of standoff sensing like risk assessment. Further work will be done in the future to improve the match by taking the instrumental factors into account.

The encouraging agreement between simulated and retrieved data highlights the proposed retrieval method as a promising first step towards a validated method, used to enhance and extend the utility and the applicability of LWIR hyperspectral standoff gas plume sensing.

Applying the suggested comparison methodology on a larger and more diverse field test data set is required in order to complete the validation process and to include quantitative uncertainty analysis. Some of the worthwhile appli- 
cations of a completely validated retrieval method are:

1) An accurate input for risk assessment models after the remote detection and identification of hazardous gas plume.

2) Providing a robust research measurement tool for the validation of more sophisticated atmospheric dispersion models which are needed for complex terrain and urban environments. It can also support a risk assessment and modeling which is solely based on remotely sensed experimental field test data.

3) The proposed method can partially (or in some cases even totally) replace the use of a massive pre deployed net of point samplers that is extensively used in transport models validation field tests. These nets form a heavy logistic burden and severely limit the number of the possible runs that can be conducted in a specific time frame (deployment and collection times and the need for a specific wind direction). Our method eliminates all the mentioned above requirements and provides a flexible test planning and reporting in real time. It unlocks the tight decoupling between the need for limited specific atmospheric conditions to the possibility of conducting a field test release.

4) The high spectral resolution of hyperspectral sensors opens the option of simultaneous dissemination and tracking the dispersion of two or even three different atmospheric tracers released from different heights or spots or release methods. It can provide a new type of data and insights for risk assessment and modeling that has not been available so far. The retrieval algorithm can be improved in the future by eliminating the need for a clear background and uniform air temperature along LOS. It is a required fundamental step towards applying this method for air (and space) borne slant path gas plume quantitative sensing.

\section{Conflicts of Interest}

The authors declare no conflicts of interest regarding the publication of this paper.

\section{References}

[1] Stremme, W., Krueger, A., Harig, R. and Grutter, M. (2012) Volcanic $\mathrm{SO}_{2}$ and $\mathrm{SiF}_{4}$ Visualization Using 2-D Thermal Emission Spectroscopy-Part 1: Slant-Columns and Their Ratios. Atmospheric Measurement Techniques, 5, 275-288. https://doi.org/10.5194/amt-5-275-2012

[2] Farley, V., Chamberland, M., Lagueux, P., Vallières, A., Villemaire, A. and. Giroux, J. (2007) Chemical Agent Detection and Identification with a Hyperspectral Imaging Infrared Sensor. Imaging Spectrometry XII, San Diego, 28-29 August 2007, 66610L. https://doi.org/10.1117/12.736731

[3] Coșofreț, B., Konno D., Faghfouri, A., Kindle H., Gittins C., Finson M., Janov T., Levreault M., Miyashiro R. and Marinelli, W. (2009) Imaging Sensor Constellation for Tomographic Chemical Cloud Mapping. Applied optics, 48, 1837-1852. https://doi.org/10.1364/AO.48.001837

[4] Watremez, X., Marblé, A., Baron, T., Marcarian, X., Dubucq, D., Donnat, L., et al. (2018) Remote Sensing Technologies for Detecting, Visualizing and Quantifying Gas Leaks. SPE International Conference and Exhibition on Health, Safety, Security, 
Environment, and Social Responsibility, Abu Dhabi, 16-18 April 2018, SPE-190496-MS. https://doi.org/10.2118/190496-MS

[5] Tremblay, P., Savary, S., Rolland, M., Villemaire, A., Chamberland, M., Farley, V., et al. (2010) Standoff Gas Identification and Quantification from Turbulent Stack Plumes with an Imaging Fourier-Transform Spectrometer. Advanced Environmental, Chemical, and Biological Sensing Technologies VII, Orlando, 5-6 April 2010, 76730H. https://doi.org/10.1117/12.850127

[6] Flesch, T.K., Wilson, J.D., Harper, L.A., Todd, R.W. and Cole, N.A. (2007) Determining Ammonia Emissions from a Cattle Feedlot with an Inverse Dispersion Technique. Agricultural and Forest Meteorology, 144, 139-155. https://doi.org/10.1016/j.agrformet.2007.02.006

[7] Sabbah, S., Harig, R., Rosch, P., Eichmann, J., Keens, A. and Gerhard, J.-H. (2012) Remote Sensing of Gases by Hyperspectral Imaging: System Performance and Measurements. Optical Engineering, 51, Article ID: 111717.

https://doi.org/10.1117/1.OE.51.11.111717

[8] Min, I.A., Abernathy, R.N. and Lundblad, H.L. (2002) Measurement and Analysis of Puff Dispersion above the Atmospheric Boundary Layer Using Quantitative Imagery. Journal of Applied Meteorology and Climatology, 41, 1027-1041. https://doi.org/10.1175/1520-0450(2002)041\%3C1027:MAAOPD\%3E2.0.CO;2

[9] Hirsch, E. and Agassi, E. (2005) Remote Detection of $\mathrm{SF}_{6}$ Plumes in a Stable Boundary Layer. European Symposium on Optics and Photonics for Defence and Security, Bruges, 26-29 September 2005, 59880G.

[10] Larrieux, E.R. (2009) Performance Evaluation of Chemical Plume Detection and Quantification Algorithms. Electrical and Computer Engineering Master's Theses, Northeastern University, Boston. http://hdl.handle.net/2047/d10019297

[11] Harig, R., Grutter, M., Matz, G., Rusch, P. and Gerhard, J. (2007) Remote Measurement of Emissions by Scanning Imaging Infrared Spectrometry. 8th International Conference on Emissions Monitoring, Zürich, 5-6 September 2007, 34-39.

[12] Hirsch, E. and Agassi, E. (2007) Detection of Gaseous Plumes in IR Hyperspectral Images using Hierarchical Clustering. Applied Optics, 46, 6368-6374.

https://doi.org/10.1364/AO.46.006368

[13] Hirsch, E. and Agassi E. (2010) Detection of Gaseous Plumes in IR Hyperspectral Images-Performance Analysis. IEEE Sensor, 10, 732-736. https://doi.org/10.1109/JSEN.2009.2038188

[14] Gerhart, T., Sunu, J., Lieu, L., Merkurjev, E., Chang, J.-M., Gilles, J. and Bertozzi, A.L. (2013) Detection and Tracking of Gas Plumes in LWIR Hyperspectral Video Sequence Data. SPIE Defense, Security, and Sensing, Baltimore, 29 April-3 May 2013, 87430J. https://doi.org/10.1117/12.2015155

[15] Tochon, G., Chanussot, J., Dalla Mura, M. and Bertozzi, A.L. (2017) Object Tracking by Hierarchical Decomposition of Hyperspectral Video Sequences: Application to Chemical Gas Plume Tracking. IEEE Transactions on Geoscience and Remote Sensing, 55, 4567-4585. https://doi.org/10.1109/TGRS.2017.2694159

[16] Puckrin, E., Turcotte, C.S., Gagnon, M.-A., Basted, J., Farley, V. and Chamberland, M. (2012) Airborne Infrared Hyperspectral Imager for Intelligence, Surveillance, and Reconnaissance Applications. SPIE Defense, Security, and Sensing, Baltimore, 23-27 April 2012, Article ID: 836004. https://doi.org/10.1117/12.918251

[17] Agassi, E., Hirsch, E., Chamberland, M., Gagnon, M.-A. and Eichstaedt, H. (2016) Detection of Gaseous Plumes in Airborne Hyperspectral Imagery. SPIE 9824, Chemical, Biological, Radiological, Nuclear, and Explosives (CBRNE) Sensing XVII, Bal- 
timore, 12 May 2016, 98240U. https://doi.org/10.1117/12.2222142

[18] Gagnon, M., Tremblay, P., Savary, S., Farley, V., Lagueux, P. and Chamberland, M. (2014) Airborne Thermal Hyperspectral Imaging of Urban and Rural Areas. IEEE Geoscience and Remote Sensing Symposium, Quebec City, 13-18 July 2014, 1369-1372. https://doi.org/10.1109/IGARSS.2014.6946689

[19] Blake, T.A., Kelly, J.F., Gallagher, N.B., Gassman, P.L. and Johnson, T.J. (2009) Passive Standoff Detection of RDX Residues on Metal Surfaces via Infrared Hyperspectral Imaging. Analytical and Bioanalytical Chemistry, 395, 337-348. https://doi.org/10.1007/s00216-009-2907-5

[20] Rivard, B., et al. (2014) First Geological Case Study of the Airborne Longwave Hyperspectral Hyper-Cam System, Thetford Mines. IEEE Geoscience and Remote Sensing Symposium, Quebec City, 13-18 July 2014, 4025.

[21] Harley, J.L., Blunck, D.L., Rankin, B.A., Gore, J.P. and Gross, K.C. (2014) Imaging Fourier Transform Spectrometer Measurements of a Turbulent Non-Premixed Jet Flame. Optics Letters, 39, 2350-2353. https://doi.org/10.1364/OL.39.002350

[22] Rhoby, M.R., Blunck, D.L. and Gross, K.C. (2014) Mid-IR Hyperspectral Imaging of Laminar Flames for 2-D Scalar Values. Optics Express, 22, 21600-21617.

https://doi.org/10.1364/OE.22.021600

[23] Yousefi, B., Sojasi, S., Castanedo, C.I., Beaudoin, G., Huot, F., Xavier, P.V., Maldague, X., Chamberland, M. and Lalonde, E. (2016) Mineral Identification in Hyperspectral Imaging Using Sparse-PCA. Proc. SPIE 9861, Thermosense: Thermal Infrared Applications XXXVIII, Baltimore, 11 May 2016, 986118.

https://doi.org/10.1117/12.2224393

[24] Warren, R.E., Cohn, D.B., Gagnon, M.-A. and Farley, V. (2015) Detecting Liquid Contamination on Surfaces, Using Hyperspectral Imaging Data. Proceedings of the 2015 SPIE Defense+Security, Baltimore, 20-24 April 2015, 94550M. https://doi.org/10.1117/12.2176617

[25] Pasquill, F. (1961) The Estimation of the Dispersion of Windborne Material. Meteor Mags, 90, 33-49. https://doi.org/10.2172/5118833

[26] https://hitran.org/xsc/

[27] Briggs, G.A. (1973) Diffusion Estimation for Small Emissions, ATDL Contributions File No. (Draft) 79, Air Resources Atmospheric Turbulence and Diffusion Laboratory. National Oceanic and Atmospheric Administration, Oak Ridge. https://doi.org/10.2172/5118833

[28] Gifford, F.A. (1976) Turbulent Diffusion-Typing Schemes: A Review. Nuclear Safety, 17, 68-86.

[29] Golder, D. (1972) Relation among Stability Parameters in the Surface Layer. Boundary-Layer Meteorology, 3, 47-58. https://doi.org/10.1007/BF00769106

[30] Mitchell Jr., E.A. (1982) A Comparison of Short-Term Dispersion Estimates Resulting from Various Atmospheric Stability Classification Methods. Atmospheric Environment (1967), 16, 765-773. https://doi.org/10.1016/0004-6981(82)90394-8 